\title{
The analysis of fretting wear in forced-in joint with the induction-hardened shaft
}

\author{
Sławomir Kowalski
}

State University of Applied Sciences Nowy Sącz, Institute of Engineering, Zamenhofa 1A, 33-300 Nowy Sącz, Poland, email: skowalski@pwsz-ns.edu.pl

\begin{abstract}
Subject to the analysis was a tribological kinematic pair consisting of shaft and sleeve, both made of C45 steel. The elements were joined by pressing with the $0.02 \mathrm{~mm}$ tolerance. The shaft was subjected to the finishing and strengthening treatment consisting in induction hardening. The tribological kinematic pair made in such way was tested on a fatigue testing machine, which permitted obtaining a rotational bending moment.

Macroscopic investigations of the unhardened shaft demonstrated, on the shaft surface, the traces of fretting wear in the form of a ring of the uniform width comprising the entire axle seat circumference.

Based on the test results, it may be concluded that the use of the shaft induction hardening process has caused the reduction of fretting wear development compared to shafts without additional treatment. In this case, Wear traces in the form of small diameter ring comprising the entire shaft circumference are observed on one side of the shaft axle seat.
\end{abstract}

Keywords: fretting wear, wheel set, press-fit joint, induction-hardened shaft

\section{Introduction}

Forced-in joints are commonly used for joining cylindrical or conical elements which are most often subject to loads causing a variable torque or bending moment. The appropriate design of the fit guarantees joint inseparability even in the harshest operation conditions. Many advantages of that assembly technology, which may include, for example, ensuring the alignment of the parts joined together, encourage scientists to pursue scientific research permitting the mechanisms accompanying the forcing process to be recognised more precisely. Simulation tests are conducted, too, making use of relevant computer software, and tests on real objects. Works [1-4] may be given as examples of scientific literature.

The main causes of the destruction of push fit joints include micro lost motion at the mating surfaces of the shaft pin and sleeve, and fretting wear, whose extent is related to the state of deformations and stresses in the joint [5-6]. Fretting wear may cause cavities in the common joint surface and/or the rise of microcracks. In the presence of variable bending loads, microcracks may develop into fatigue fractures. In turn, cavities may lead to joint breaking, rotation or disconnection [7-9].

Elements loaded with forces causing the rotational bending moment, especially those elements which are subject to high loads and which influence safety directly, should be distinguished by appropriate fatigue strength.
Rail vehicle wheel sets are an example of such elements, on which travel safety depends directly. The wheel/axle push fit joint is subject to both static loads from the vehicle weight and to dynamic loads caused by the vehicle move-

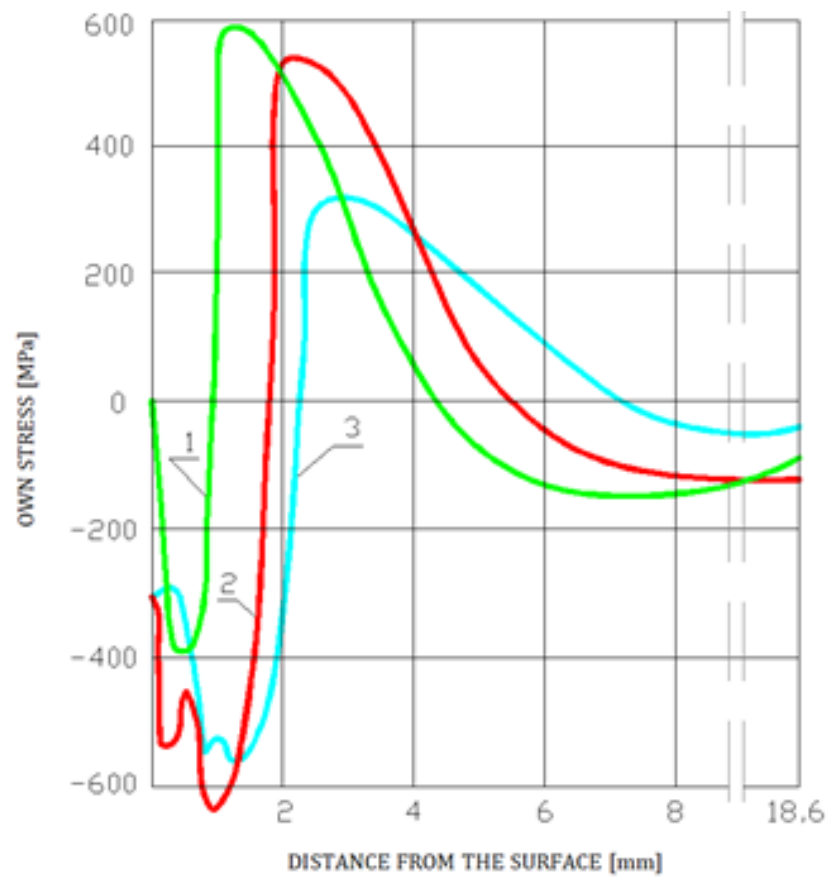

Fig. 1. Internal stresses in C45 steel samples hardened to the depth of: $1-1 \mathrm{~mm}, 2-1.8 \mathrm{~mm}, 3-2.3 \mathrm{~mm}$ [20] 


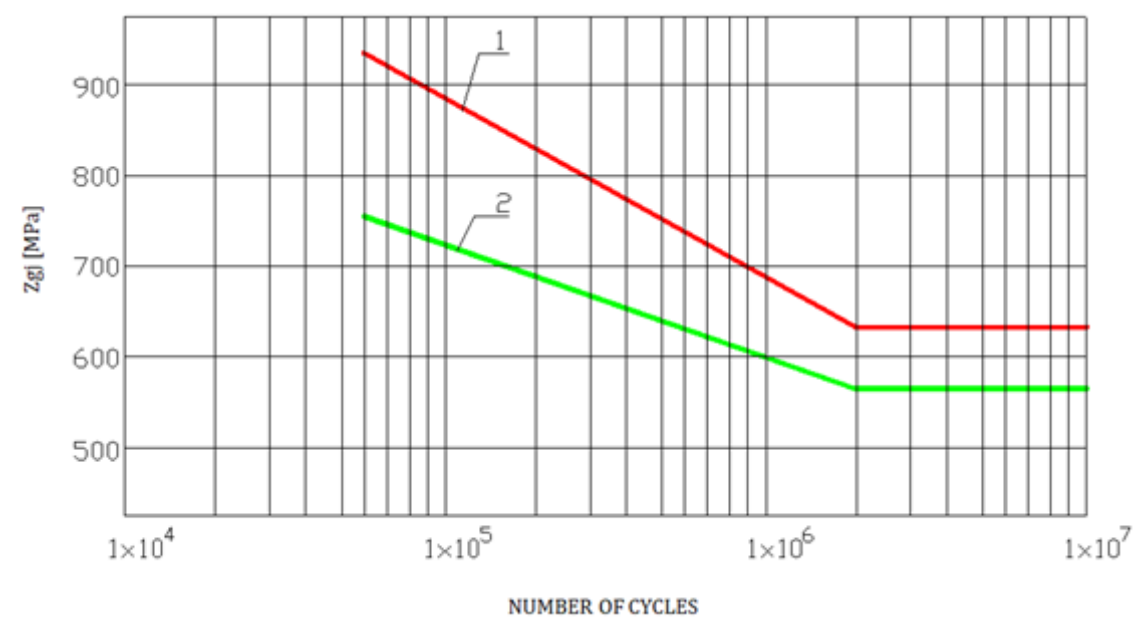

Fig. 2. Fatigue strength of heat-improved and induction-hardened steel to the depth of $1-1.35 \mathrm{~mm}, 2-0.9 \mathrm{~mm}, 3-2.3 \mathrm{~mm}$ [18]

ment along the track. Such load accumulation may lead to the initiation of premature fatigue wear, as a result of the development of fretting wear. It is difficult to diagnose a forced-in joint for damage during routine inspections, which increases the risk of causing the wear during operation and, consequently, causing vehicle derailing.

The use of finish treatment consisting in surface hardening of forced-in joint elements may be one of the methods to increase the life of joint elements subject to rotational bending.

Increasing the surface hardness by surface hardening can be done by two methods: flame or induction. The latter is used more frequently owing to several advantages. Induction hardening consists in steel heating above the austenite transition point with the use of eddy currents, and then quick cooling to obtain the bainitic structure. Induction hardening is commonly used in order to improve the properties of the elements, which is mainly the implication of low technology costs in exchange for satisfactory final outcomes. Induction hardening causes the increase of surface hardness and the reduction of impact strength. The material's fatigue limit, especially the ultimate tensile strength, also increases [10].

Owing to the wide use of the surface hardening process, many works on the subject can be found in literature. These are the works whose authors, making use of computer software, model the stress distribution, for example in [11-16] or empirical tests concerning the influence of the microstructure and residual stresses on the tribological performance of induction-hardened steel. Work [17] may be an example here.

The fatigue strength of hardened steel depends on many factors, which may include, for example, the geometrical dimensions of the top layer, the microstructure and hardening depth.

The influence of hardening depth on the distribution of internal stresses is shown in figure 1 . The hardening depth values shown are the implication of the most frequently used depths of induction hardening by means of high fre- quency currents. The concentration of tensile stresses located under the harder layer decreases noticeably with the increase of the thickness of the hardened top layer. Given the increase of the hardened surface thickness by 1 to 2 $\mathrm{mm}$, the reduction of tensile stresses by $9-12 \%$ is observed. The area of occurrence of maximum tensile stresses moves deeper into the material where, in the case of loading with torque and bending moments, much lower working stresses occur [18].

The increase of the fatigue strength of steel subjected to the hardening process is explained by the advantageous distribution of internal stresses, that is those which are distinguished by low residual stresses spreading out within the non-hardened zone [18]. The presence of residual compressive stresses in the external layers of hardened elements enhances their fatigue strength even by $20 \%$ [19]. The pattern of fatigue strength for induction-hardened steel in relation to the number of fatigue cycles and hardening depth is presented in figure 2.

The fatigue strength of push fit joints is a complex phenomenon and depends on many factors, both external and internal. One of the causes of joint strength reduction is the activity of the engineering notch, which brings about the concentration of disadvantageous stresses and the reduction of surface pressures. The next cause, however, especially in the case of push fit joints operating in rotational bending conditions, is the development of fretting wear. Small surface pressures enhance the development of fretting wear due to the easier relative displacement of the mating surfaces.

Fretting wear develops as a result of the mating of two elements in relation to which there occur oscillatory tangential microdisplacements of an insignificant amplitude. In view of the abundance of devices meeting the criterion above, fretting wear commonly occurs in many branches of science and technology. Wear traces were noted, for example, on a truck frame [21], airplane elements [22-23], rail vehicle elements [24] and orthopaedic implants [25-26].

In the case of forced-in joints, it is difficult to diagnose 


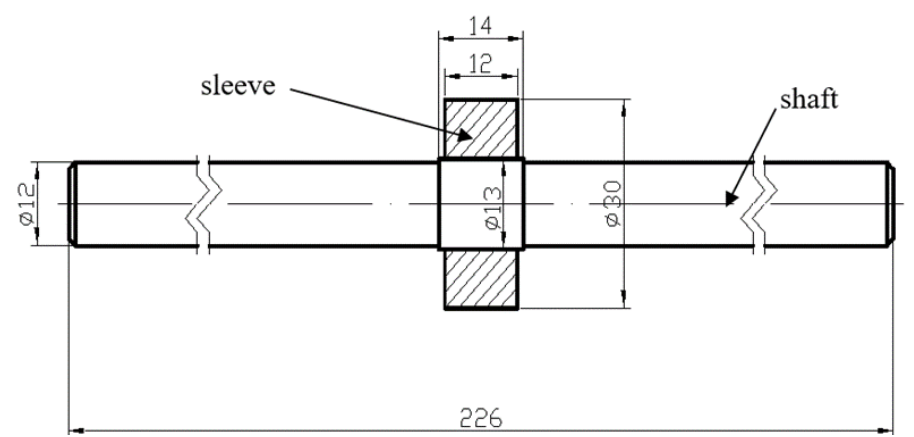

Fig. 3. Sample dimensions

the development of fretting wear during operation, which may, as a consequence, lead to fatigue cracks. The disassembly of the joint involves its destruction and the lack of the option to reuse the same elements, especially the sleeve which is most often cut open. That is why appropriate preventive measures reducing wear development should be used. Shaft surface hardening may be one of them.

Based on the description of the fretting wear development mechanism in a forced-in joint as provided in literature, the roughness of the surfaces being joined together is a decisive factor for the actual contact between the surfaces joined and, consequently, for the initiation of fretting wear. The main phenomenon initiating the development of fretting wear in a forced-in joint is adhesion, however. Adhesive bonds appear in the area of the actual contact between the surfaces being joined together, as a result of loading the elements with a normal force and the occurrence of oscillatory tangential displacements between the mating surfaces.

The purpose of these investigations is to assess the influence of shaft induction hardening on the development of fretting wear in forced-in joints subjected to a rotational bending moment. The assumed wear test conditions may simulate the operation of a rail vehicle wheel set.

\section{Test methodology}

The object of the investigations is a tribological kinematic pair consisting of a shaft and sleeve joined together by pressing. The dimensions of the sample are shown in the figure 3 . The assumed sleeve/shaft tolerance is 0.02 $\mathrm{mm}$. Elements were made of C45 steel whose basic mechanical properties are as follows:

$$
\begin{aligned}
& \mathrm{R}_{\mathrm{e}}=540 \mathrm{MPa} \\
& \mathrm{R}_{\mathrm{m}}=700 \mathrm{MPa} \\
& \mathrm{A}=17.5 \% \\
& \mathrm{E}=215 \mathrm{GPa}
\end{aligned}
$$

The value of surface nominal pressures between the shaft and sleeve as determined by the finite element method (FEM) was $139.7 \mathrm{MPa}$.

Wear tests were conducted for two sample groups. The first one comprised non-hardened shafts, and the other induction-hardened ones. Nine tribological kinematic pairs

\begin{tabular}{|c|c|}
\hline $\begin{array}{l}\text { Shaft surface } \\
\text { roughness } \\
\text { profile }\end{array}$ & Fig. 4a \\
\hline
\end{tabular}
were tested in each group. The parameters of the shaft top
Table 1 The parameters of the top layer of tested shafts

\begin{tabular}{lcc} 
Description & $\begin{array}{c}\text { The shaft without } \\
\text { top layer hardening } \\
\text { treatment }\end{array}$ & $\begin{array}{c}\text { The shaft after additional } \\
\text { top layer treatment by } \\
\text { means of induction } \\
\text { hardening }\end{array}$ \\
\hline $\begin{array}{l}\text { Average top } \\
\text { layer hardness } \\
{[\mathrm{HB}]}\end{array}$ & 170 & 650 \\
\hline $\begin{array}{l}\text { Surface } \\
\text { roughness } \\
\text { parameters } \\
\text { Ra/Rz }[\mu \mathrm{m}]\end{array}$ & $1.63 / 7.59$ & $1.79 / 9.50$ \\
\hline
\end{tabular}

\begin{tabular}{lcc}
\hline $\begin{array}{l}\text { Pressing force } \\
\text { diagram }\end{array}$ & Fig. 5a & Fig. 5b \\
\hline $\begin{array}{l}\text { Maximum } \\
\text { value of the } \\
\text { pressing force } \\
P_{w}[k N]\end{array}$ & 8.0 & 8.6 \\
\hline
\end{tabular}
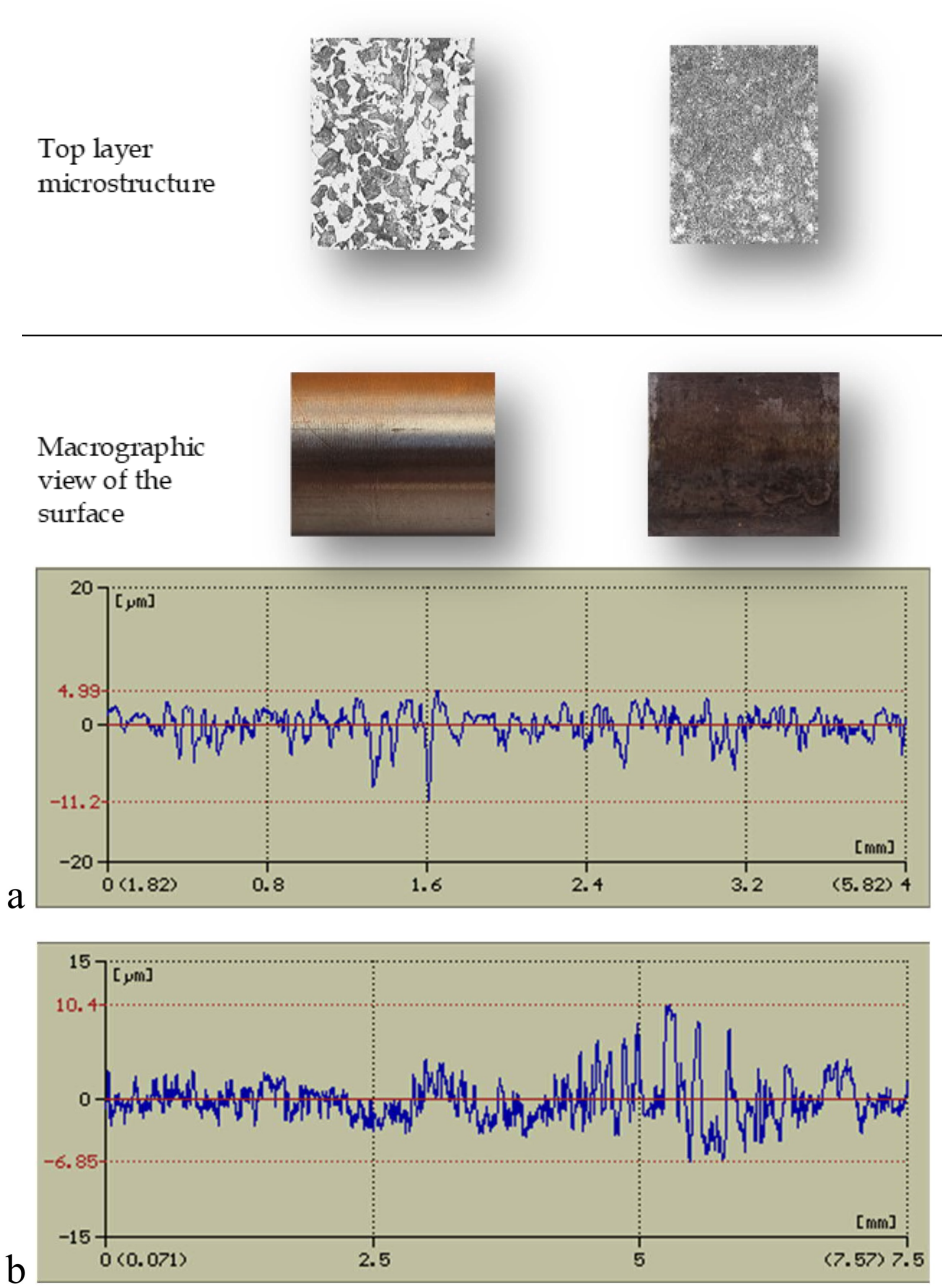

Fig. 4. Shaft surface roughness profile, a) the shaft without top layer hardening treatment, b) the shaft after additional top layer treatment by means of induction hardening

layer in both sample groups are collated in table 1 . The internal sleeve surface was ground, owing to which the 

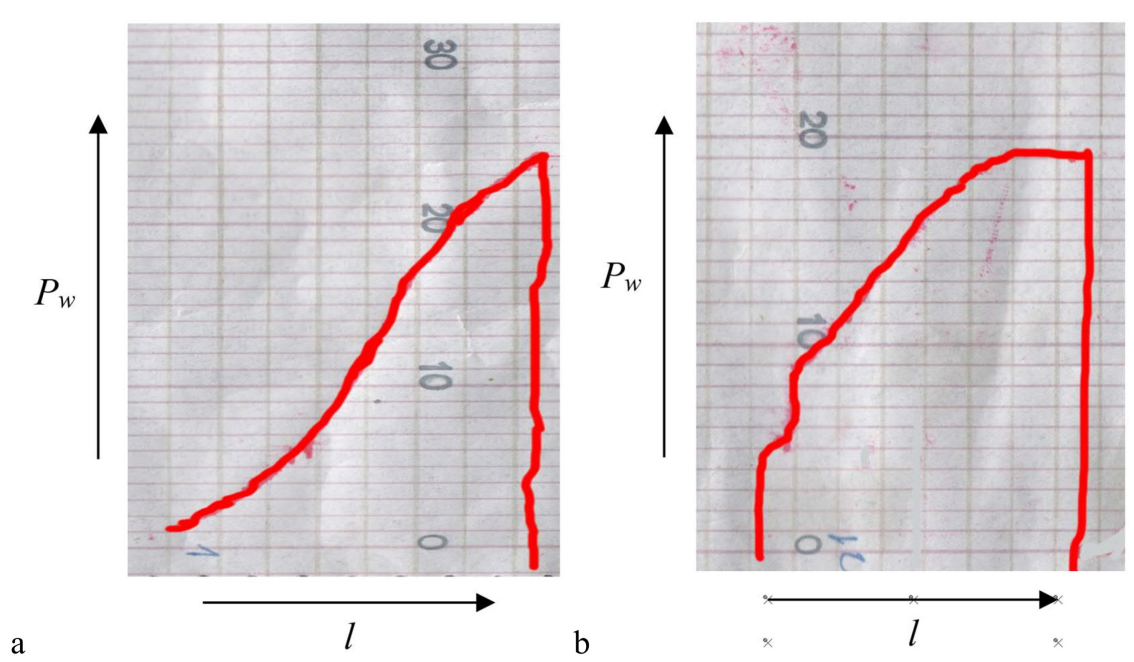

Fig. 5. Pressing force diagram, a) the shaft without top layer hardening treatment, b) the shaft after additional top layer treatment by means of induction hardening

surface roughness parameter $\mathrm{Ra}=0.3 \mu \mathrm{m}$ was obtained. Sleeve surface hardness was $160 \mathrm{HB}$.

It follows from table 1 that the hardness of the surface of the elements subjected to the induction hardening process increased approximately four times, which directly influenced the process of sleeve pressing onto the shaft. The force needed to press the sleeve increased by $0.6 \mathrm{kN}$. The growth of the force needed to press the sleeve onto the shaft and the change of the characteristics of the diagram $\mathrm{P}_{\mathrm{w}}(l)$ may be due to the considerable difference of shaft surface hardness in relation to sleeve surface hardness. That situation may cause the rise of adhesive bonds, which requires a greater pressing force.

\section{Hardening process}

Shaft induction hardening consisted in rapid heating of the top layer with eddy currents induced by high frequency alternating current of the power at the level of $2 \mathrm{~kW}$ flowing in an inductor in the form of winding, and then quick cooling by a liquid spray. The shaft hardening process is presented schematically in figure 6.

As a result of induction hardening, stress distribution in the shaft top layer as presented in figure 7 was achieved. These values were determined experimentally with the use of the ANSYS program. In the shafts subjected to induction hardening, there occur axial and circumferential compression stresses as well as tensile radial stresses, whose value varies in the range from 1.3 to $10 \mathrm{MPa}$.

\section{Test bench}

The test bench, on which fatigue tests were conducted, permitted a load on a sample to be achieved in such a way as to make it possible to obtain an appropriate amplitude of oscillatory tangential displacements between the surfaces joined together, as necessary for fretting wear, if any, to arise. The way of application of the forces and the appropriate structure of the machine caused the generation of the rotational bending moment.

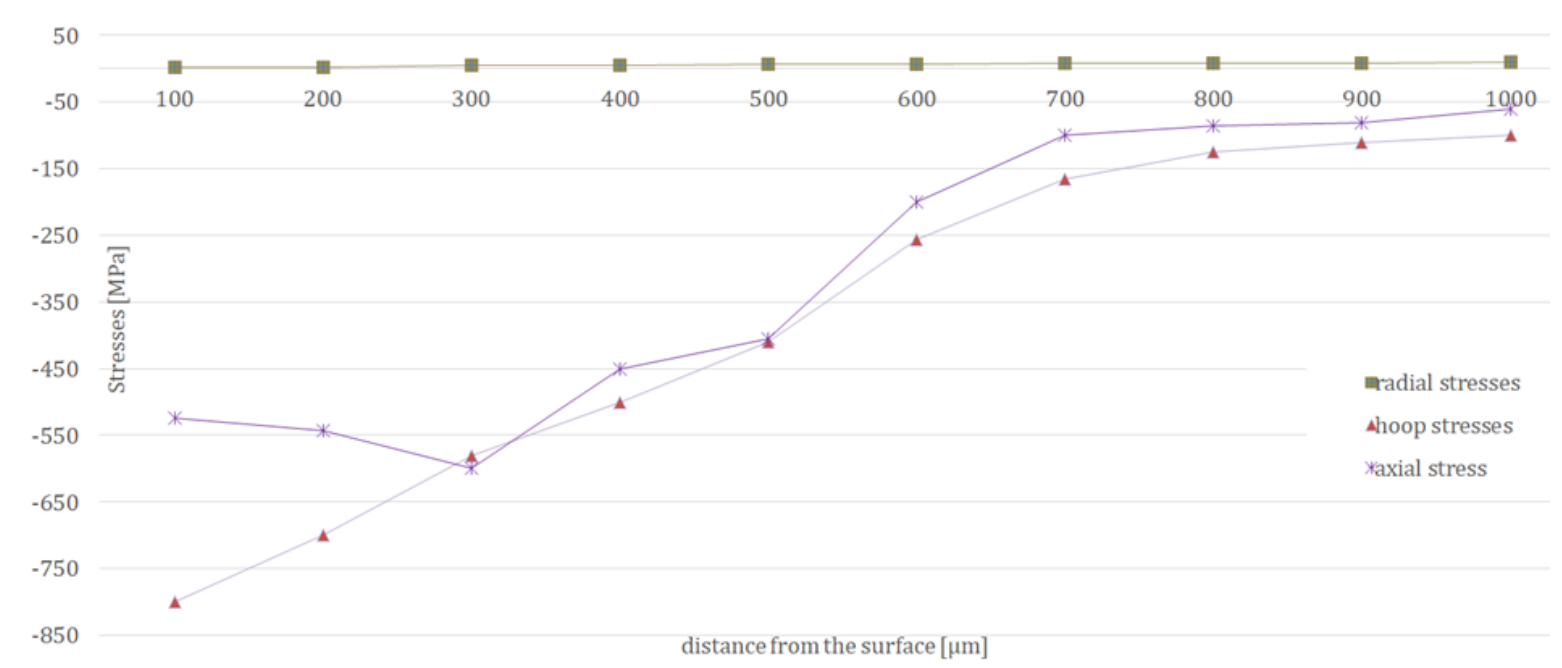

Fig. 7. Stress distribution on induction-hardened shafts 

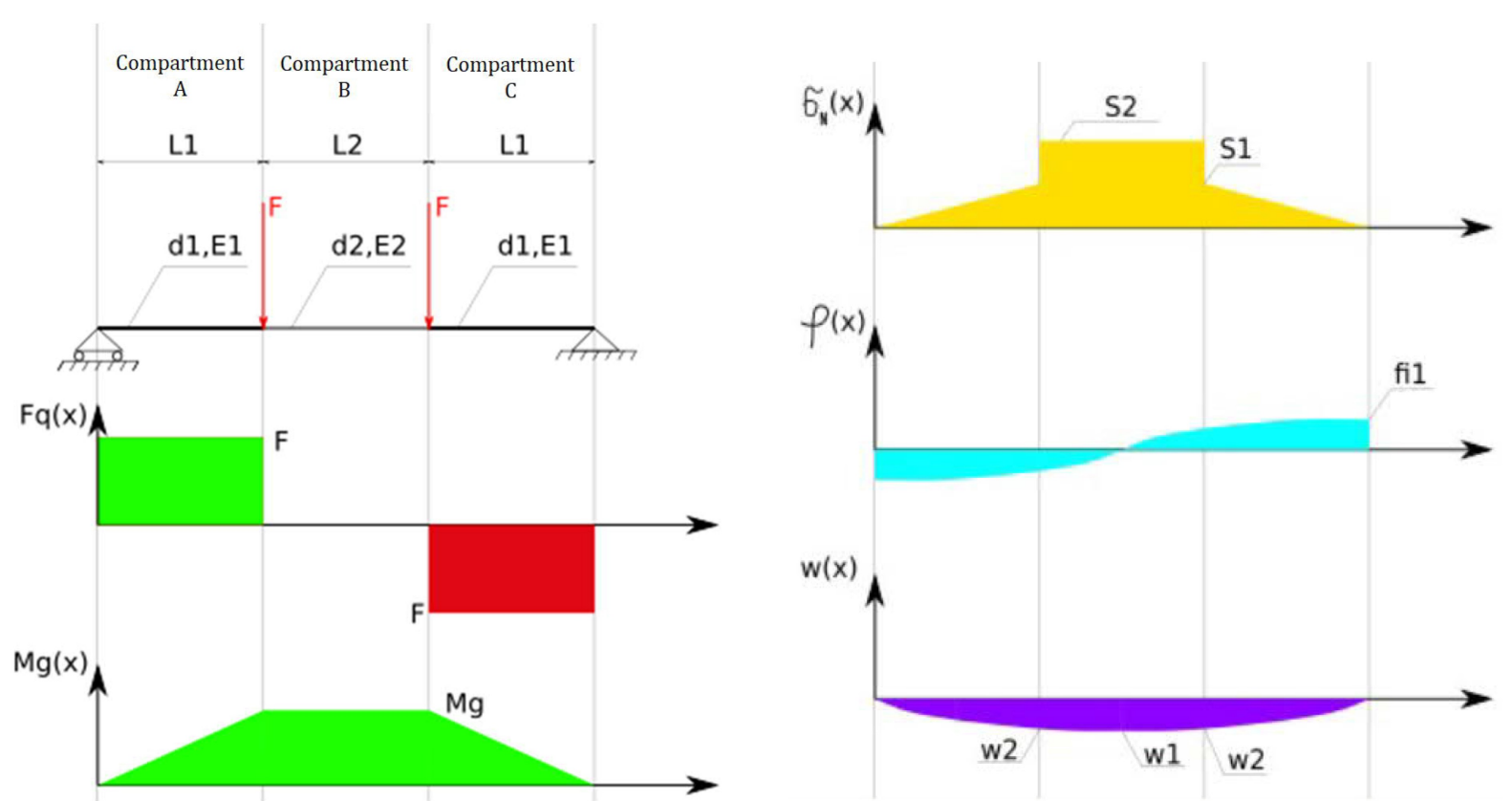

Fig. 8. The method of loading the tribological kinematic pair and strength results

Table 2 Results of the strength analysis of a sample loaded is in figure 4

\begin{tabular}{ccccccccc}
$\begin{array}{c}\text { Shaft } \\
\text { load }\end{array}$ & $\begin{array}{c}\text { Bending } \\
\text { moment }\end{array}$ & \multicolumn{3}{c}{ Normal stresses } & $\begin{array}{c}\text { Deflection } \\
\text { angle }\end{array}$ & Deflection line & \multicolumn{2}{c}{$\begin{array}{c}\text { Compartment } \\
\text { length }\end{array}$} \\
\hline $\mathbf{F}_{\mathrm{c}}[\mathbf{N}]$ & $\mathbf{M g}[\mathbf{N m}]$ & $\begin{array}{c}\text { S1 } \\
{[\mathbf{M P a}]}\end{array}$ & $\begin{array}{c}\text { S2 } \\
{[\mathbf{M P a}]}\end{array}$ & $\mathbf{f i 1}\left[{ }^{\circ}\right]$ & $\begin{array}{c}\mathbf{w 1} \\
{[\mathbf{m m}]}\end{array}$ & $\begin{array}{c}\mathbf{w 2} \\
{[\mathbf{m m}]}\end{array}$ & $\begin{array}{c}\text { L1 } \\
{[\mathbf{m m}]}\end{array}$ & $\begin{array}{c}\text { L2 } \\
{[\mathbf{m m}]}\end{array}$ \\
\hline 400 & 44 & 56 & 259.4 & 1.38 & -3.9 & -2.6 & 110 & 226
\end{tabular}

The parameters of sample tests at the fatigue testing machine were as follows:

- Sample revolutions: $\mathrm{n}=1360 \mathrm{rev} . / \mathrm{min}$,

- Load on the sample: $F_{c}=2 \times 200=400 \mathrm{~N}$,

- Number of cycles: $n=10^{7}$

\section{Strength analysis of shafts subjected to wear tests}

A non-linear material model with isotropic strengthening was used for the strength analysis (in the issue under investigation, the influence of the load and relief was not considered, hence it was insignificant if a model with isotropic or kinematic strengthening was assumed). The material stress level is determined in accordance with the Huber -Mises-Hencky (HMH) stress hypothesis. The material model was created on the basis of simplified data presented at the beginning of this chapter. The loading method and the results of the strength analysis are presented in figure 8 and table 2 .
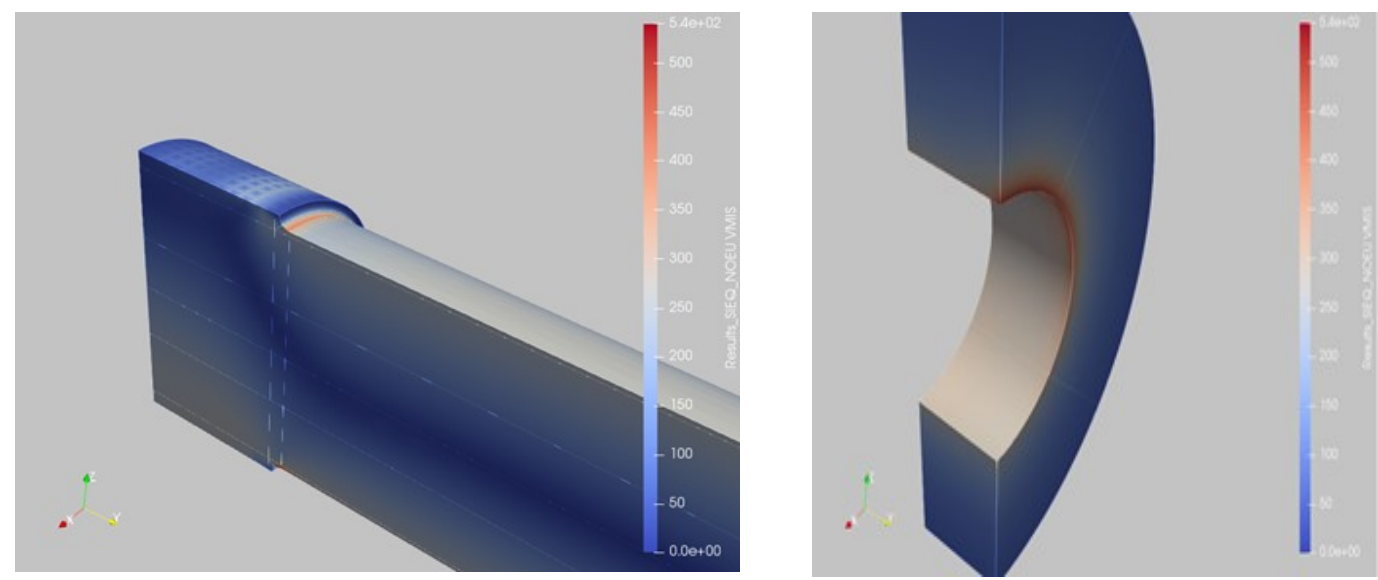

Fig. 9. Results of the FEM analysis of the shaft/sleeve joint - loads reduced in accordance with the HMH hypothesis [MPa] 

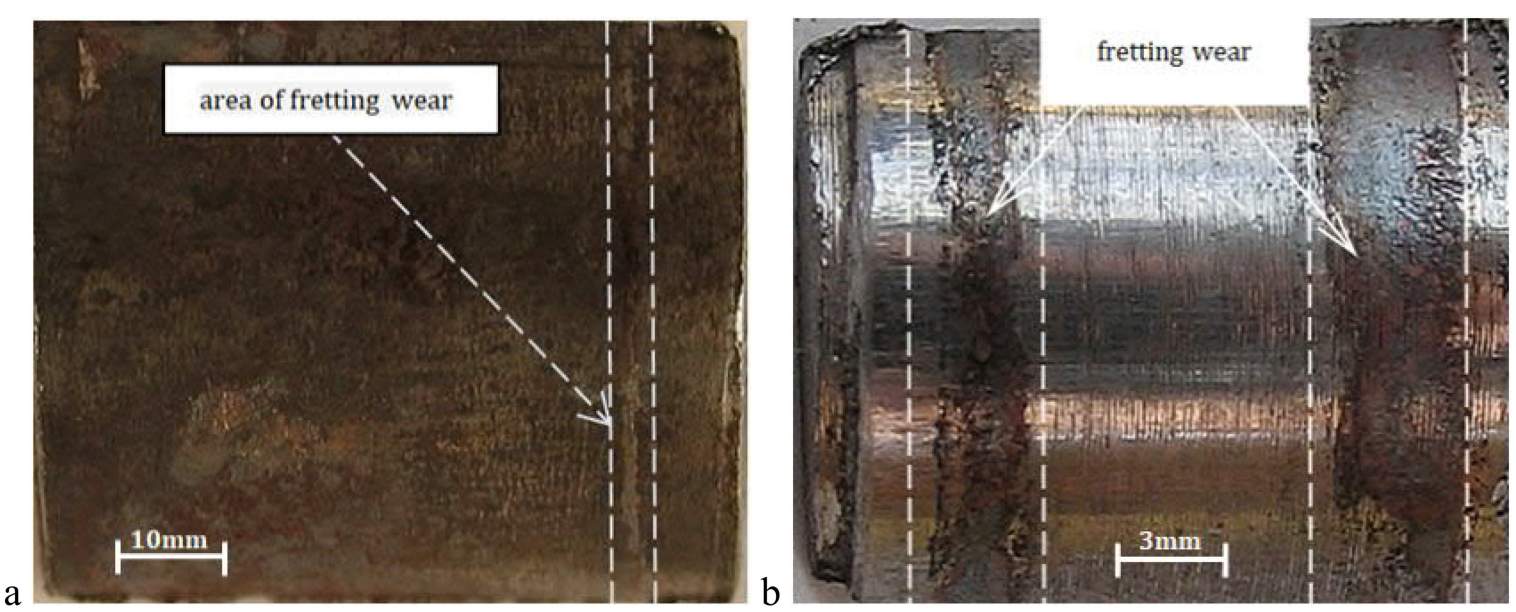

Fig. 10. Shaft surface after fatigue tests: a) the hardened shaft, b) the non-hardened shaft

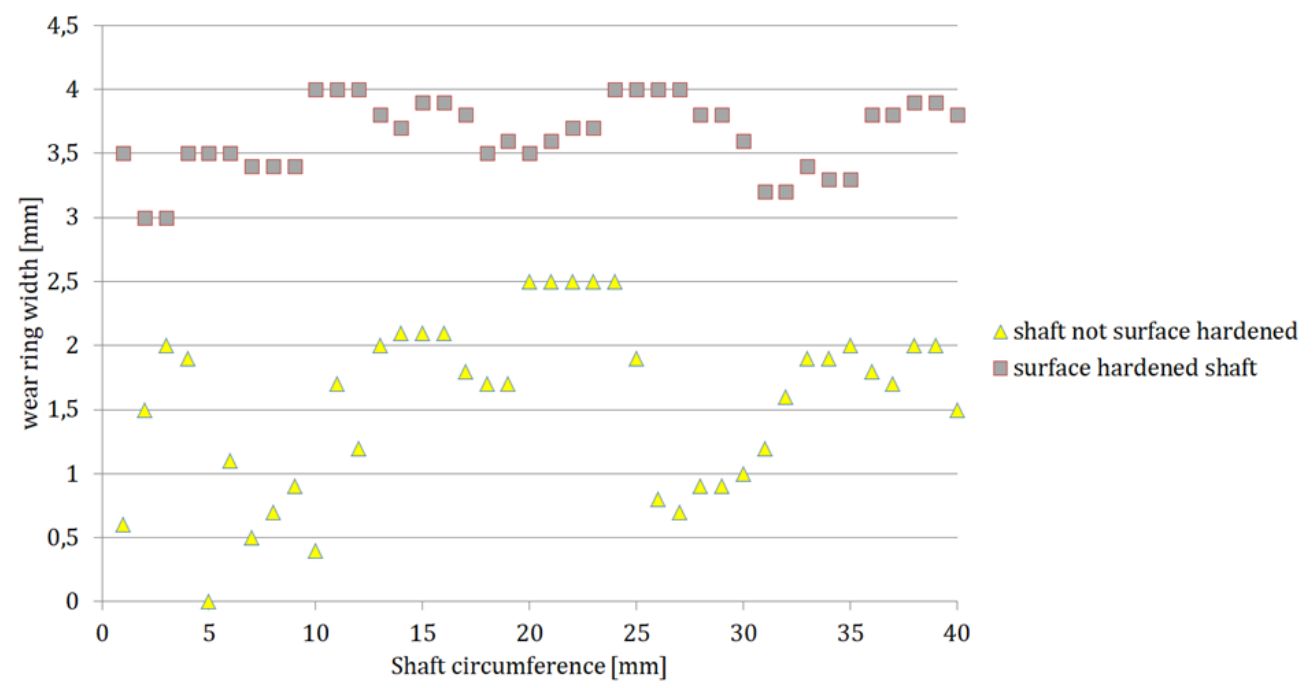

Fig. 11. Distribution of wear traces on the shaft circumference

\section{FEM and fatigue analysis of the tribological kinematic pair}

In the FEM analysis, the geometrical model is a piece of beam taken from the whole beam from the range in which the bending moment is the only external load. The model consists of a quarter of the real object. The condition requiring symmetry in relation to the XZ plane was imposed on the front surfaces, and the condition requiring symmetry in relation to the $\mathrm{YZ}$ plane was imposed on the remaining surfaces.

The sleeve image is deliberately non-static in the $\mathrm{Z}$ direction because non-linear contact formulation with the required contact at the initial course of the analysis was applied. The bending moment on the system comprises two forces applied as in figure 8. The results of the FEM analysis are presented in figure 9. In the case of the shaft, the maximum reduced stress occurs in the section change area, which may cause the engineering notch phenomenon thus reducing the joint fatigue strength.

\section{Procedure of sample preparation for laboratory tests}

To assess the degree of wear of tribological kinematic pairs, a relevant joint disassembly procedure was prepared as the traditional forcing off of the sleeve from the shaft would cause the distortion of the actual condition of the contact surface between the elements. After cutting off the shaft ends, the joint was cut long its axis of symmetry. As a result, three samples were obtained, which were subjected to the following laboratory tests:

- $\quad$ macroscopic tests of the sleeve surface mating with the shaft surface to assess the size of wear traces,

- macroscopic tests of the shaft surface to assess the size of wear traces, and microscopic observations permitting the assessment of the kinds of wear comprised by fretting wear,

- microscopic tests of the surface of the sleeve and shaft contact surface to assess the condition of the top surfaces and any wear products in the gap. 

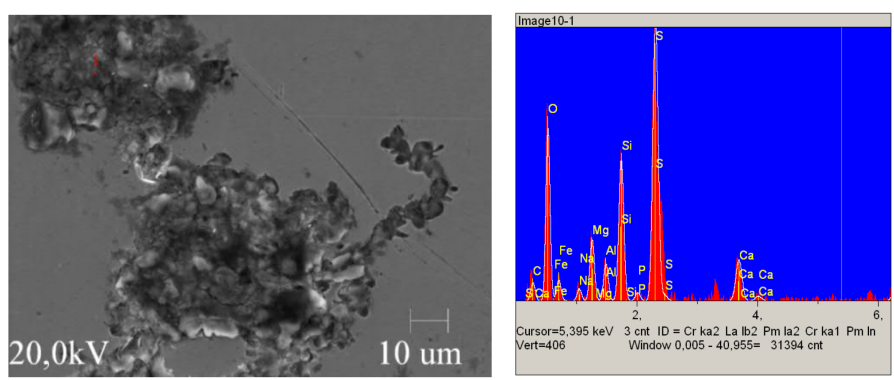

\begin{tabular}{|c|c|c|c|c|c|}
\hline Elt. & Conc & Units & Line & $\begin{array}{l}\text { Intensity } \\
\text { (c/s) }\end{array}$ & $\begin{array}{l}\text { Error } \\
2 \text {-sig }\end{array}$ \\
\hline $\mathrm{C}$ & 20,154 & wt. \% & $\mathrm{Ka}$ & 8,25 & 1,049 \\
\hline $\mathrm{O}$ & 30,168 & wt. \% & $\mathrm{Ka}$ & 72,03 & 3,099 \\
\hline $\mathrm{Fe}$ & 33,462 & wt. \% & $\mathrm{Ka}$ & 399,11 & 7,294 \\
\hline $\mathrm{Na}$ & 0,706 & wt. \% & $\mathrm{Ka}$ & 5,54 & 0,859 \\
\hline $\mathrm{Mg}$ & 2,310 & wt. \% & $\mathrm{Ka}$ & 29,24 & 1,974 \\
\hline $\mathrm{Al}$ & 1,139 & wt. \% & $\mathrm{Ka}$ & 18,19 & 1,557 \\
\hline $\mathrm{Si}$ & 3,615 & wt. \% & $\mathrm{Ka}$ & 71,43 & 3,086 \\
\hline $\mathrm{P}$ & 0,214 & wt. \% & $\mathrm{Ka}$ & 4,29 & 0,756 \\
\hline$S$ & 7,049 & wt. \% & $\mathrm{Ka}$ & 151,66 & 4,496 \\
\hline $\mathrm{Ca}$ & 1,184 & wt. \% & $\mathrm{Ka}$ & 25,88 & 1,858 \\
\hline
\end{tabular}

Fig. 12. Analysis of the chemical composition of wear products on the shaft surface

\section{Test results}

The results of the macrographic observations of shaft surfaces are presented in figure 7 . In the case of hardened shafts, fretting wear traces are visible on the right side of the axle seat (fig. 10a). The trace comprises the entire shaft circumference and has the form of a ring of irregular dimensions. The wear trace width in the widest place is approximately $2.5 \mathrm{~mm}$. Non-hardened shafts are distinguished by wear traces visible on both sides of the shaft axle seat surface (fig. 10b). The wear trace width in the widest place is $4 \mathrm{~mm}$. The size of wear traces at each millimetre of the shaft axle seat surface was measured by means of a microscope and the results are presented in figure 11. The ring width on the non-hardened shaft varies between 3 and $4 \mathrm{~mm}$; in the case of hardened shafts that trace is thinner and its width varies between 0.1 and $2.5 \mathrm{~mm}$.

The brown colour of the hardened shaft surface hinders the identification of wear traces which are brown-grey, a colour typical of atmospheric corrosion of iron, which is the evidence of the oxidation of worn-out areas. The gap between the shaft and sleeve, which arises as a result of shaft deflection under the load, permits the contact of the damaged areas with oxygen, which manifests itself in the precisely that colour.

Both in the case of non-hardened and hardened shafts,
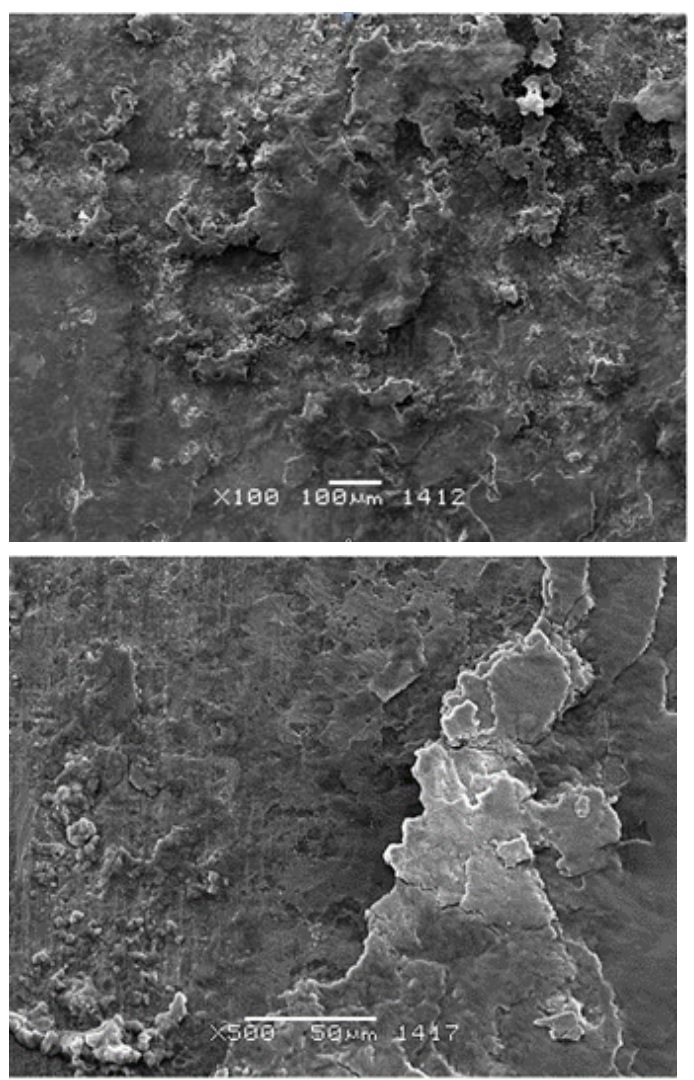

Fig. 13. Sample images of fretting wear observed on the shaft surface

wear traces are located close to the edge of the joint with the sleeve. Fretting wear location only by the forced-in joint edges is related to the presence of oscillatory tangential displacements between the mating surfaces. The quantity which confirms the presence of oscillatory tangential displacements in the joint is the amplitude of relative displacements of the mating surfaces. In joints operating in rotational bending conditions, the distribution of tangential stresses close to the contact surface of the elements joined together will be as on the Völkening model [27]. The value of those stresses equals zero in the joint symmetry axis and increases to the maximum by the sleeve front surface. That means that the amplitude of oscillations in the case of their occurrence will reach the maximum value at the contact point of the front sleeve surface with the shaft surface, and zero in the centre plane.

The investigations of the chemical composition on a scanning microscope equipped with an EDS analyser confirm the presence of oxygen in wear products occurring on the shaft surfaces. The results of the analysis are presented in figure 12. Wear products are distinguished by oxygen content of approximately $30 \%$, which confirms their strong oxidation. The remaining chemical elements noticeable in the wear products are the outcome of engineering preparation of the surfaces for testing.

The microscopic investigations of the shaft surface areas affected by wear products (the results of the observations presented in figure 13) with the use of the scanning 

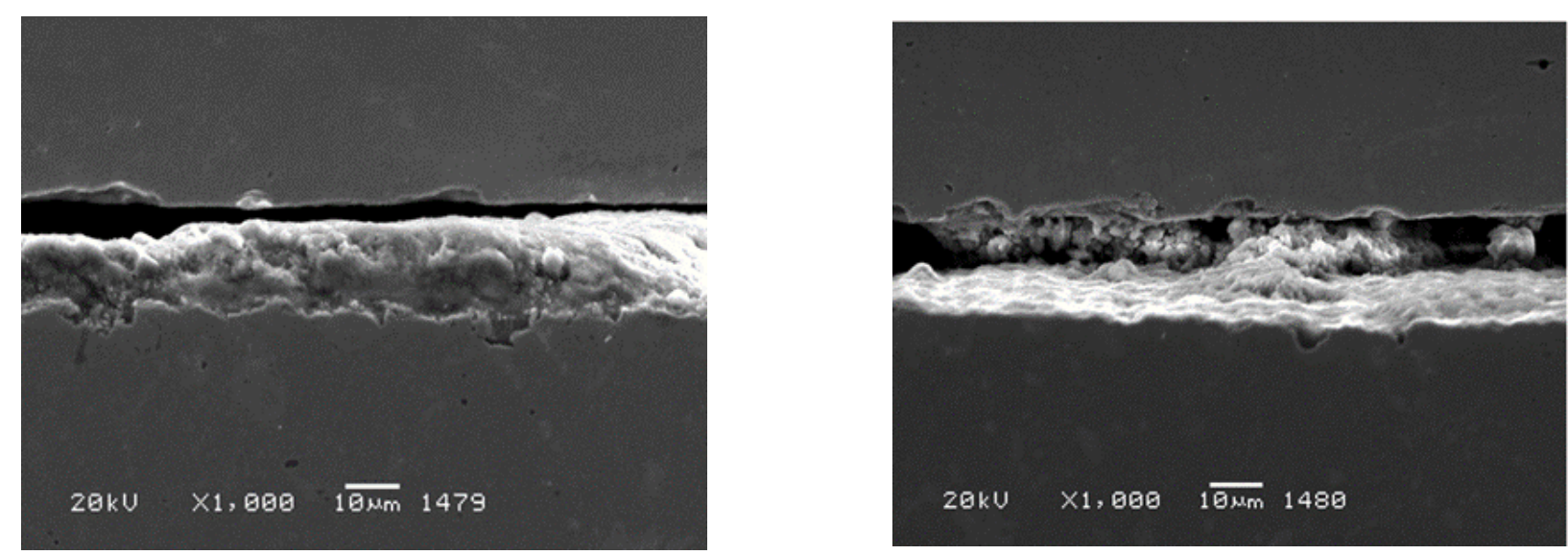

Fig. 14. The microscopic observations of the shaft and sleeve contact surface
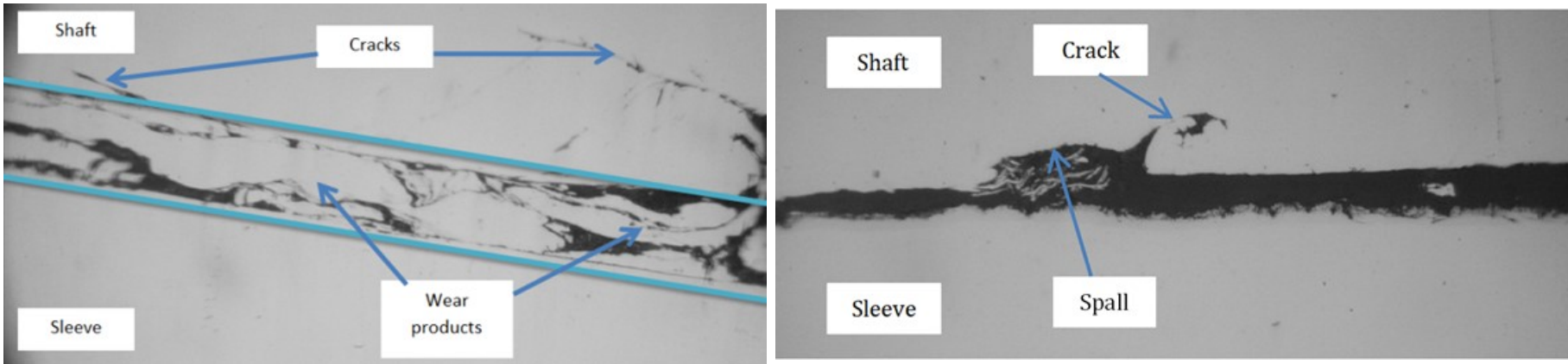

Fig. 15. Sample results of metallographic observations with the recorded microcracks of the shaft top layer

microscope have demonstrated that the formation of material build-ups on the shaft surface is the dominant damage. During fatigue tests, those build-ups became plastically deformed. They also have a tendency to break and move. Moving and torn-off products cause damage to the further parts of the surface thus enhancing the development of fretting wear.

The microscopic observations of the shaft and sleeve contact surface (fig. 14) have demonstrated the presence of wear products. In places, especially in the central part of the joint, visible are sizeable deposits of wear products which filled both the space between the shaft and sleeve, and the microgaps on the surface of the elements. Also visible are the disintegrated fragments of the shorn microirregularities on the surface of the elements, such microirregularities having the shape of small balls tending to move, which may cause additional microdamage.

After surface hardening, the top layer is distinguished by high hardness, that is why intensive tearing off of the microprojections on the sleeve surface will take place when the shaft is pressed onto the sleeve, the hardness of the latter being nearly four times lower. Torn-off microprojections will gather in microgaps in the initial and partly central part of the joint. As the sleeve front becomes closer, the quantity of wear products is reduced and the actual contact of the first bodies may be noticed.

High shaft surface hardness in combination with insig- nificant sleeve surface roughness parameters will cause the plastic deformation of the sleeve top layer during pressing, which may contribute to the initiation of fretting wear.

Metallographic observations have demonstrated the microcracks of the top layer of the mating elements. Microcracks occur in the area where fretting wear traces are visible. Sample images on which shaft microcracks were recorded are presented in figure 15 .

Top layer plastic deformations arisen as a result of sleeve pressing onto the shaft, and the operation conditions of the tribological kinematic pair which cause shaft deflection during fatigue tests, have probably become the source of the initiation of fatigue microcracks of the top layer. Each time, the beginning of the microcrack occurs on the joint surface, and then develops at an angle deeper into the material. In some places, the chipping of the particles of the top shaft layer is noted, those particles then moving along and causing further damage.

The shafts subjected to the surface hardening process became fatigue-worn and cracked at $8 \times 10^{7}$ cycles. Figure 16 shows the sample macrographic images of the tribological kinematic pair fracture.

The breaking mechanism was a classical one for the elements operating in rotational bending conditions. Two zones are conspicuous. Zone I (the fatigue fracture) is distinguished by a surface which is smoothed as a result of wall grinding in. The fatigue fracture occupies $85 \%$ of the 

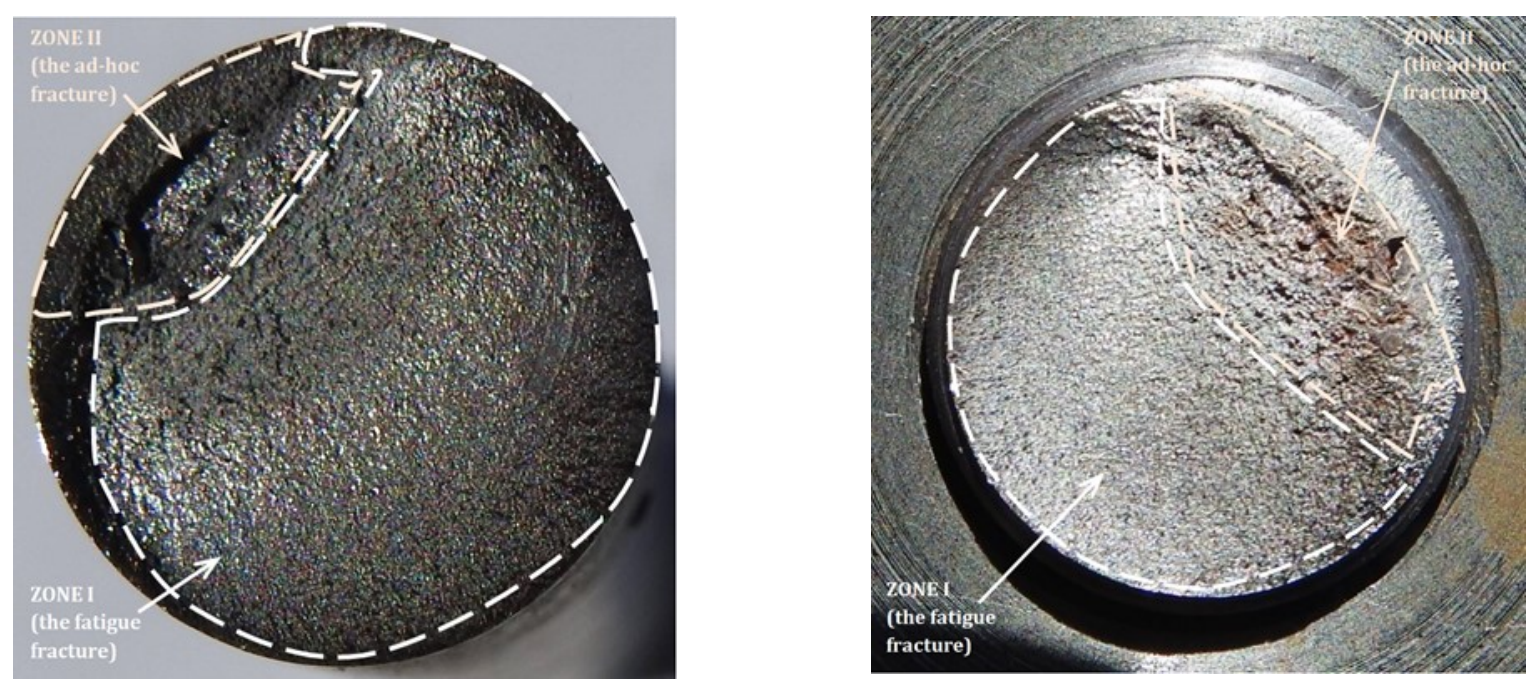

Fig. 16. Macrographic image of the tribological kinematic pair fracture

entire surface, which is the outcome of the loads with the preset value $(400 \mathrm{~N})$ acting on the tribological kinematic pair and of the relevant stresses. Zone II (the ad-hoc fracture) has the nature of a brittle fracture without visible plastic deformations. It is in that zone where the samples demonstrate a coarse-graded fracture, and visible on the surface are fatigue lenses which are situated under the hardened layer.

Laboratory test results have confirmed the theoretical analysis claiming that fatigue cracks will occur at the place of stress accumulation. In the case under analysis, that place is the one where the shaft diameter changes. An additional crack source, which could contribute to joint destruction, is microcracks resulting from the hardening process and developing at the boundary of the core and strengthened layer.

Based on the analysis of fatigue cracks, four peculiar phases of the fatigue phenomenon may be distinguished [18]:

- plastic deformation of a local nature,

- cyclical strengthening and weakening,

- nucleation and microcrack development,

- microcrack combination leading to a fatigue fracture.

Fatigue cracks come into being and develop along lost motion strips, whose rise is related to the free surface. The process of the creation of local plastic deformations is based on the "weak link" principle. The principle assumes that a single grain or group of grains on a surface of the material, under a variable load, operates in different conditions than the operation conditions of the core of the material. Located in a most disadvantageous position in relation to the load, those grains demonstrate lower strength than the surrounding ones. Such a zone deforms plastically, whilst the remaining part of the material continues to perform in the elastic deflection conditions [18].
The relationship between average tangential stresses and the number of cycles is shown in figure 17. Based on the observations, three fatigue strength areas may be distinguished. In Area 1, which ends at approximately 7x102 cycles, visible are numerous plastic deformations of insignificant dimensions. In Area 2, plastic deformations are also noted, but their scale and sizes are considerably bigger than in Area 1. That phenomenon may be observed at the range from $7 \times 10^{2}$ to $4.5 \times 10^{5}$ fatigue cycles. Over $4.5 \times 10^{5}$ cycles, Area 3 may be distinguished, in which fatigue cracking is accompanied by elastic deflection of considerable greater magnitude than plastic deformation. Sample fracture takes place in that area at approximately $2 \times 10^{7}$ fatigue cycles. It should be emphasized, however, that the values above are approximate because it is difficult to specify the range limits due to the lack of clear symptoms of a change of the phenomena accompanying cracking.

\section{Conclusion}

The purpose of the tests whose results are presented in this article was to assess the development of fretting fatigue in forced-in joints subjected to loads generating the rotational bending moment, where the shaft top layer was subjected to additional treatment by induction hardening.

The tests have demonstrated that all the tribological kinematic pairs had fretting wear traces which were one of the causes of the development of fatigue cracks. Those traces occurred in the area of the sleeve and shaft joint edges each time. The amount of fretting wear intensity was diversified and dependent on the final form of the top layer. The surfaces of the hardened shafts were characterized by smaller traces of wear. Non-hardened shafts are, however, distinguished by wear traces in the form of a ring of a considerably greater width than hardened shafts, moreover, those traces are visible on either side of the axle seat. The place of wear confirms the fretting wear development mechanism described by the authors of [28], and also proves the correctness of the fatigue tests to have been con- 


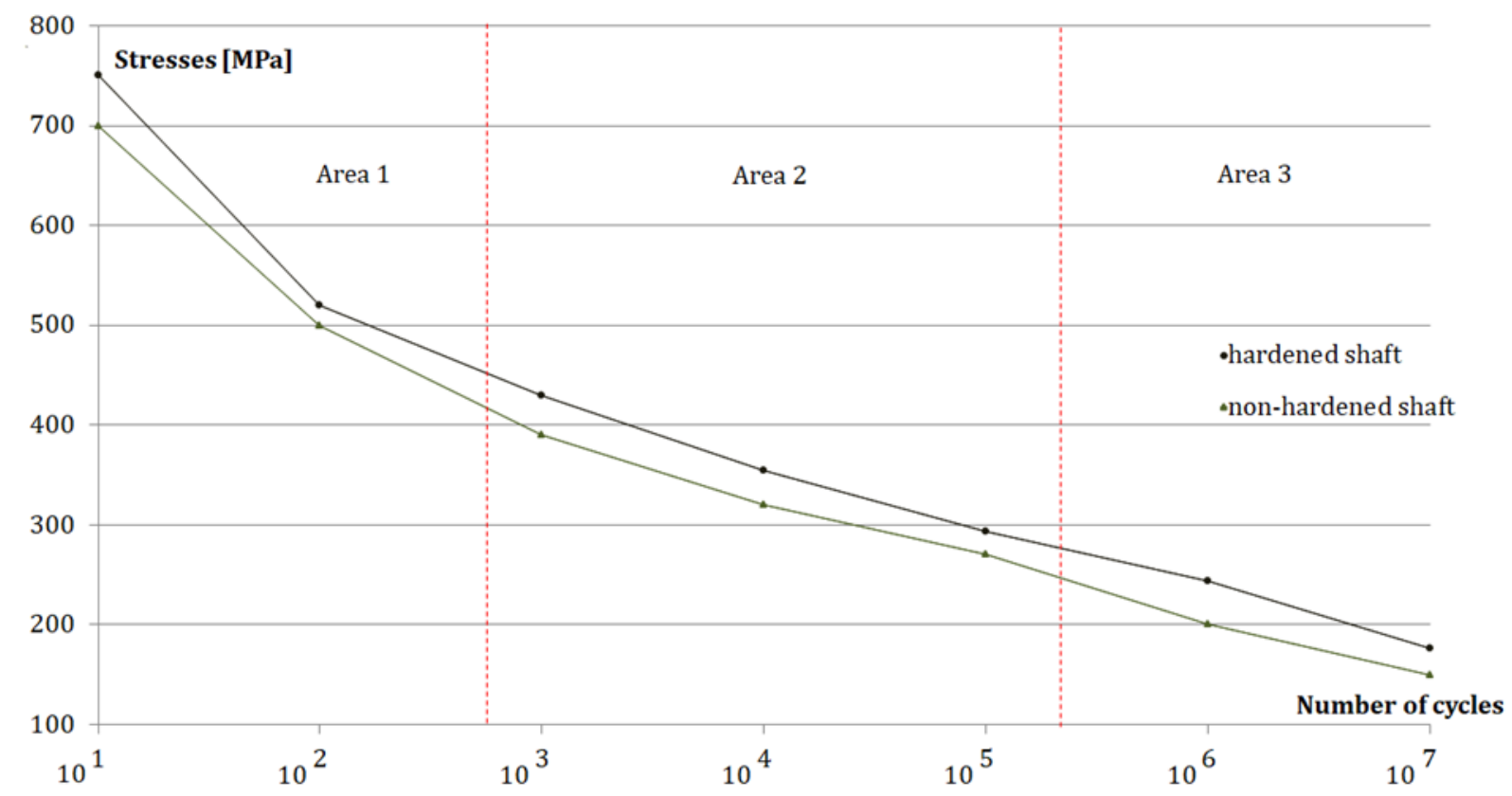

Fig. 17. The relationship between average tangential stresses and the number of cycles.

ducted. Material build-ups from the shearing of microirregularities on the surface of the elements being joined together are the main component of fretting wear. In addition to material build-ups, microcracks of the top layer and micropits at the surface of the elements are observed.

In the case of forced-in joints, it is difficult to determine the wear precisely because joint disassembly is impossible. It is assumed, however, that the first wear traces appear at $10^{3}$ fatigue cycles. The investigations with a flow detector, at precisely that number of cycles, demonstrated insignificant defects which most probably originate from fatigue microcracks producing fretting wear. To confirm that, the joint would have to be dismantled and ultrasonic test results verified. As the main objective of these investigations was, however, to determine the influence of shaft surface hardening on shaft fatigue life and on the development of fretting wear, joint disassembly and reassembly would distort the image of wear due to the physical and chemical changes occurring during joint assembly and tests.

Complex physical phenomena accompanying wear tests and the very process of sleeve pressing onto the shaft, which may include grooving, micromachining, oxidation, adhesion and friction, hindered the interpretation of the results. Any changes within the range of the accompanying phenomena may affect the development of fretting wear.

The top shaft layer hardening process positively influenced the development of fretting wear and shaft fatigue strength. The operation time needed to destroy the joint increased four times in relation to non-hardened shafts.

Macro and microscopic observations of fatigue fractures also demonstrated the presence of fatigue centres both at the place of the shaft section change and under the hardened layer. Cracks originated in the observed fretting wear zone, grew larger in time and moved to the place of change of the sample section, where stresses accumulated as a result of the existing engineering notch, which caused sample cracking.

\section{References}

[1] Hu J., Zhanga K., Xub Y., Chenga H., Xua G., Lia H. Modeling on bearing behavior and damage evolution of single-lap bolted composite interference-fit joints. Composite Structures 2019; 212: 452-464, https:// doi.org/10.1016/j.compstruct.2019.01.044

[2] Zuo Y., Cao Z., Zheng G., Zhang Q. Damage behavior investigation of CFRP/Ti bolted joint during interference fit bolt dynamic installation progress. Engineering Failure Analysis 2020; 111: 104454, https:// doi.org/10.1016/j.engfailanal.2020.104454

[3] Sniezek L., Zimmerman J., Zimmerman A. The carrying capacity of conical interference-fit joints with laser reinforcement zones. Journal of Materials Processing Technology 2010; 210: 914-925, http:// dx.doi.org/10.1016/j.jmatprotec.2010.02.004

[4] Seung Woo Lee S.W., Lee D.G. Torque transmission capability of composite-metal interference fit joints. Composite Structures 2007; 78: 584-595, https:// doi.org/10.1016/j.compstruct.2005.11.021

[5] Grudziński K., Gąska A. Calculation of the load capacity of the flat interference joint taking into account local slips. XVII Sympozjum PKM, Wydawnictwo Politechniki Lubelskiej, Lublin-Nałęczów 1995: 301306.

[6] Ciuła, J., Gaska, K., Siedlarz, D., Koval, V. Management of sewage sludge energy use with the application of bi-functional bioreactor as an element of pure production in industry. E3S Web Conference 2019, 123, 01016, https://doi.org/10.1051/ 


\section{e3sconf/201912301016.}

[7] Bielawski P. Wear margin of ship machine units with press fits. Nondestructive testing and diagnostics 2018; 3: 13-15, https:// doi.org/10.26357/ BNiD.2018.015

[8] Ciuła J., Gaska K., Generowicz A., Hajduga G. Energy from Landfill Gas as an Example of Circular Economy, E3S Web of Conferences 2018, 30, 03002, https://doi.org/10.1051/e3sconf/20183003002.

[9] Gaska, K., Generowicz, A., Lobur, M., Jaworski, N., Ciuła, J., Vovk, M. Advanced algorithmic model for poly-optimization of biomass fuel production from separate combustible fractions of municipal wastes as a progress in improving energy efficiency of waste utilization. E3S Web of Conference 2019, 122, 01004. https://doi.org/10.1051/e3sconf/201912201004.

[10] Pomykała K., Skibińska A. Hardening steel, classification, composition and characteristics of quenching oils. Nafta-Gaz 2016; 4: 285-293, https:// doi.org/10.18668/NG.2016.04.08

[11] Barglik J., Smalcerz A., Przylucki R., Doležel I. 3D modeling of induction hardening of gear wheels. Journal of Computational and Applied Mathematics 2014; 270: 231-240, https://doi.org/10.1016/ j.cam.2014.01.019

[12] Coupard D., Palin-Luc T., Bristiel P., Ji V., Dumas Ch. Residual stresses in surface induction hardening of steels: Comparison between experiment and simulation. Materials Science and Engineering: A, 2008; Vol. 487, 1-2: 328-339, https:/ / doi.org/10.1016/ j.msea.2007.10.047

[13] Hömberg D., Liu Q., Montalvo-Urquizo J., Nadolski D., Petzold T., Schmidt A., Schulz A. Simulation of multi-frequency-induction-hardening including phase transitions and mechanical effects. Finite Elements in Analysis and Design 2016; 121: 86-100, https://doi.org/10.1016/j.finel.2016.07.012

[14] Tong D., Gu J, Yan F. Numerical simulation on induction heat treatment process of a shaft part: Involving induction hardening and tempering. Journal of Materials Processing Tech. 2018; 262: 277-289, https://doi.org/10.1016/j.jmatprotec.2018.06.043

[15] Gao K., Qin X., Wang Z., Chen H., Zhu S., Liu Y., Song Y. Numerical and experimental analysis of 3D spot induction hardening of AISI 1045 steel. Journal of Materials Processing Technology 2014; 214: 24252433, https://doi.org/10.1016/ j.jmatprotec. 2014.05 .010

[16] Hömberg H., Petzold T., Rocca E. Analysis and simulations of multifrequency induction hardening. Nonlinear Analysis: Real World Applications 2015; 22: 8497, https://doi.org/10.1016/j.nonrwa.2014.07.007

[17] Cao Y.J., Sun J.Q. Ma F., Chen Y.Y., Cheng X.Z., Gao X., Xie K. Effect of the microstructure and residual stress on tribological behavior of induction hardened GCr15 steel. Tribology International 2017; 115: 108-

\section{5, https://doi.org/10.1016/j.triboint.2017.05.028}

[18] Karwala K., Kulikowski H., Tułecki A. Technological problems of wheelset durability in terms of adapting rail vehicles to increased speeds. PhD thesis.

Politechnika Krakowska. Kraków. Poland; 1991.

[19] Skvortsov A.A, Gnatyuk E.O., Rybakova M.R., Burukin I.V. Methods for hardening and improvement of fatigue characteristics of titanium and ironchromium nickel alloy samples. Periódico Tchê Química 2020; 17: 425-436

[20] Janowski S., Szyrle W. Influence of hardening depth and low tempering temperature on stress distribution in induction hardened layers. Metaloznawstwo i Obróbka Cieplna 1980; 48

[21] Vinay N. Rao, Jeffrey W. Eischen. Failure analysis of fretting fracture in frame rails of heavy duty trucksCase study. Engineering Failure Analysis 2020; 113: 104544, https://doi.org/10.1016/ j.engfailanal.2020.104544

[22] Mangardich D., Abrari F., Fawaz Z. A fracture mechanics based approach for the fretting fatigue of aircraft engine fan dovetail attachments. International Journal of Fatigue 2019; 129: 105213, https:// doi.org/10.1016/j.ijfatigue.2019.105213

[23] Bok-Won Lee, Suh J., Lee H., Tae-gu Kim. Investigations on fretting fatigue in aircraft engine compressor blade. Engineering Failure Analysis 2011; 18: 19001908, https:// doi.org/10.1016/ j.engfailanal.2011.07.021

[24] Michnej M., Guzowski S. Fretting wear simulation in a clamped joint based on the example of a rail vehicle wheel set. Wear 2019; 438-439: 102654, https:// doi.org/10.4467/2353737XCT.15.174.4379

[25] Geringer J., Forest B., Combrade P. Fretting-corrosion of materials used as orthopaedic implants. Wear 2005; 259: 943-951, https://doi.org/10.1016/ j.wear.2004.11.027

[26] Esguerra-Arce A., Mischler S., Moya S., Amaya C., Ipaz L., Yate L., Meza J., Aguilar Y. Atomic aluminum content $(x)$ effect on fretting-corrosion of Ti1 $-x \mathrm{~A} 1 x \mathrm{~N}$ coatings for orthopedic applications. Wear 2016; 362-363: 87-96, https://doi.org/10.1016/ j.wear.2016.05.015

[27] Völkening W. The design of the steering knuckle of roller bearing wheelsets and the selection of roller axle bearings. ZEV - Glassers Annalen 1972; 96 (1972): 3-11

[28] Guzowski S., Michnej M. Influence of technological methods increasing surface layer durability on axles fretting wear In railway wheel sets. Eksploatacja i niezawodnosc - Maintenance and Reliability 2016; 18 (1): 1-9, http:/ / dx.doi.org/10.17531/ein.2016.1.1. 